\title{
Children's Perception Scale of Head Lice Infestation (CPS-HLI): Design and Psychometrics
}

\author{
Gona Bekry (iD ${ }^{1}$, Parvin Sarbakhsh (iD) ${ }^{2}$, Hamid Allahverdipour ${ }^{1}$ and Abdolreza Shaghaghi ${ }^{1,{ }^{*}}$ \\ ${ }^{1}$ Department of Health Education \& Promotion, Faculty of Health, Tabriz University of Medical Sciences, Tabriz, Iran \\ ${ }^{2}$ Department of Biostatistics and Epidemiology, Faculty of Health, Tabriz University of Medical Sciences, Tabriz, Iran \\ "Corresponding author: Department of Health Education \& Promotion, Faculty of Health, Tabriz University of Medical Sciences, Tabriz, Iran. Email: ar.shaghaghi@gmail.com \\ Received 2020 December 22; Revised 2021 March 26; Accepted 2021 April 19.
}

\begin{abstract}
Background: Pediculosis is a common ectoparasitic infestation that involves especially the skin of children worldwide. Studying the children's perception of the disease's risk factors, the effectiveness of personal preventive measures, and its implications for their health could be a major leap forward in health promotion activities.

Objectives: This study aimed to develop and evaluate the psychometric properties of the Children's Perception Scale of Head Lice Infestation (CPS-HLI) and its initial feasibility assessment for use on Iranian and possibly other elementary school children.

Methods: The scale's items were retained based on an extensive literature search and classified into the underlying constructs of the Extended Health Belief Model (EHBM). An expert panel endorsed the qualitative content and face validity of the preliminary draft, and 47 items remained for quantitative validity testing on a sample of 362 elementary school students in the city of Paveh, West of Iran. Explanatory and confirmatory factor analyses (EFA and CFA) were employed to test the content and structural validity of the constructed instrument. Cronbach's alpha and intra-class correlation coefficients were calculated to assess the internal consistency and reliability of the scale.

Results: The values of Lawshe's content validity index(0.90) and content validity ratio(0.77), the subscales' Cronbach's alpha (0.59), and intra-class correlation (0.72) coefficients confirmed plausible internal consistency of the scale. The values of root mean square error of approximation (RMSEA) $\left(<0.08\right.$ with $\chi^{2}<0.05$ ), Tucker-Lewis Index (TLI), and Comparative Fit Index (CFI) $>0.9$ approved the applied statistical model's goodness of fit. The ranges of Kaiser-Meyer-Olkin (KMO) measure of sampling adequacy for the underlying subscales (0.49-0.74) and the statistically significant result of Bartlett's test of sphericity $(\mathrm{P}<0.001)$ confirmed the patterned relationship among the constructed scale's items. The principal component analysis that was performed using STATA favored the 11-factor solution.

Conclusions: The study findings support the construct validity of CPS-HLI for use in studies on children's perception of head lice infestation risk factors, the effectiveness of personal preventive measures, and the disease implications for their health and wellbeing. Further cross-cultural and cross-national validation studies are recommended for using the instrument in a wider range of populations and settings.
\end{abstract}

Keywords: Pediculosis, Validity, Perception, Health Belief Model, Head Lice

\section{Background}

Pediculosis, or literally called Head Lice Infestation (HLI), is a public health concern worldwide, and its epidemic has been reported in a variety of different socioeconomic population groups (1). The three main types of lice that could live on humans are Pediculus humanus capitis (head louse), Phthirus pubis (pubic louse), and P. humanus corporis (body or clothes louse) (2). All three types survive by feeding on human blood and spread more commonly by close person-to-person contact, and pets such as dogs or cats do not play a role in its transmission $(3,4)$. $P$. humanus capitis intrude mostly children of $5-12$ years old frequently (5) since they are more prone to the risk of head lice infestation due to generally close head-to-head contacts or sharing personal belongings such as hat, scarf, or combs that are the most common identified transmission routes of head lice infestation (6). The global burden of disease on individuals, families, and healthcare systems is significant in terms of disease-adjusted life years (DALYs). It was reported, for instance that almost 6 - 12 million annual cases of infestation occur only in the United States (7) that cost the country $367 \$$ million a year by virtue of lost days in schools and about $1 \$$ billion as the infestation treatment expenditure (8). 
Pediculosis is not itself a health threat or sign of poor hygiene but could be an antecedent for a variety of other physical and psychosocial health problems. The reported prevalence of lice infection worldwide is in the range of 1.8 - 87.0\% (9,10). Augmenting incidence of pediculosis in Iran has raised health concerns in recent years due to factors such as the cross-border transmission of infestation from under standard living conditions in neighborhood waraffected countries (Iraq and Afghanistan), over-crowding of classes in some elementary and secondary schools along with schools' poor building conditions and precarious personal protective measures (11). The HLI prevalence in Iran is reported to be in the range of $2.3-17.5 \%$ (11-16). Therefore, it is estimated that at least 5 - 8 million families on average are affected by the disease and its consequences. The enhancement of school children's perception about the risk factors of HLI and the effectiveness of personal preventive measures in their health and daily life well-being is recommended to be a common grand for systematic planning of preventive programs (17). However, the measurement of children's perception about a health threat or their behavioral responses to alleviate the potential harm of an illness could be a burdensome endeavor.

The challenges of conducting studies on children and their perceptions about the impact of HLI on their overall life were addressed in previous studies $(18,19)$. Data collection through the application of an invalidated instrument and sole reliance on children's responses were the main reported methodological deficiencies $(20,21)$. All these predicaments appeal for the integrated approach in researching children and the application of validated multi-dimensional tools to collect data about their health perceptions, attitudes, and health behaviors (22). Due to the lack of a gold standard data collection tool to measure school-age children's perception about HLI, this study was conducted to develop and psychometrically analyze the properties of the Children's Perception Scale of Head Lice Infestation (CPS-HLI) for application in relevant studies. The utilized theoretical framework for the assumed items' selection was the extended Health Belief Model (HBM) (23) and its different constructs.

\section{Methods}

This cross-sectional study was conducted in the city of Paveh, Kermanshah province, West of Iran, from September to October 2017. The participants consisted of 362 girls in the age range of 6 - 11 years old who were enrolled through a multistage random sampling scheme from the two selected schools with the highest prevalence rate among the five active girl schools in the previous calendar year. The sample size was decided based on the min- imum sample size recommendation for scales' psychometric studies (six participants for each scale item) (24). An additional $20 \%$ of participants were recruited to compensate for the probable study drop-outs and thus retaining a suitable power.

The inclusion criteria were informed consent of the children's parents and their willingness to allow the participation of their children in the study, and the absence of other concurrent skin or hair diseases among the study attendants. Only 343 parents returned the completed informed consent forms and acquiesced with their children's participation in the study; thus, the response rate was $94.75 \%$.

\subsection{Items Generation}

An extensive literature search was performed to identify possible questions for the assessment of children's perception about pediculosis risk factors, the effectiveness of the personal preventive measures, and the disease implications for their health and daily life. The extended HBM constructs were used as the theoretical framework to classify the pinpointed items. A preliminary list consisting of 47 items was generated with response options on a threepoint Likert type scale (yes, no, sometimes) in behavioral dimension and (agree, disagree, no idea) in the knowledge and attitude dimensions. The items were categorized in 11 dimensions in the next step based on the extended HBM constructs, i.e., perceived susceptibility, perceived severity, perceived barriers, perceived benefits, self-efficacy, cues to action, self-identity, consideration of future, concern for appearance, perceived importance, and outcome behavior. A rating score in the range of 0 - 2 was assigned to each item, and the drafted scale was sent to a panel of experts consisting of health education specialists, GPs, and parasitologists. Small modifications were made based on feedback. The Lawshe's (25) content validity ratio (CVR) and Content Validity Index (CVI) were estimated to ensure the panelists' agreement on conceptual coherence, relevance, and clarity of the items in the designed scale. The corrected version was also pilot-tested on 12 students to check the clarity, readability, and understandability of the items for students of the purposed age range. The study respondents' total and subscale mean scores with their standard deviations were estimated to assess the recruited children's degree of perception about head lice infestation risk factors, the effectiveness of personal preventive measures, and the disease implications for their health and well-being.

\subsection{Construct Validity of CPS-HLI}

Confirmatory factor analysis (CFA) was carried out to refine the theory-based assignment of items to the sub- 
scales and ascertain the structural properties of CPS-HLI (26). Considering the study sample size, factor loadings equal to or greater than 0.3 were considered to meet the minimum acceptable level of significance (27) and decided to be retained in the final version. Thus, the fit indices of root mean square error of approximation (RMSEA), TuckerLewis Index (TLI), Comparative Fit Index (CFI), Kaiser-Meyer Olkin (KMO) measure of sampling adequacy, Bartlett's test of sphericity, and principal component analysis (PCA) were employed (28).

\subsection{Internal Consistency and Reliability of CPS-HLI}

Internal consistency and reliability of the CPS-HLI were assessed by applying Cronbach's alpha for the 11 subscales of the CPS-HLI (values equal to or higher than 0.70 were deemed satisfactory) and test-retest intra-class correlation coefficient (ICC) based on the collected data from 30 study participants at a 15-day interval.

\subsection{Data Collection}

Prior arrangements were made with the local authorities of the Ministry of Education (MoE) to get permission and attend the study venues and explain the study objectives to children and schools' educational and administrative staff. The prepared informed consent sheet along with the study information leaflet had been attached to the CPSHLI, and the students were asked to hand over the package to their parents. Confidentiality of the provided information, their right to withdraw from the study without obligation in giving any reason, and also benefits of participation in the study were explained in simple words within the parents' specific information leaflets. The parents were also requested to help their first and secondgrade school children in filling out the CPS-HLI if they consented to allow their children to participate in the study.

\subsection{Ethical Consideration}

This study received approval from the regional Medical Ethics Board of Trustees (MEBoT) affiliated with the Tabriz University of Medical Sciences (approval number: IR.TBZMED.REC.1396.187). Anonymous completion of the CPS-HLI was perpetuated throughout the data collection process, and only the research's team members were given access to the filled questionnaires.

\subsection{Statistical Analysis}

The STATA version 14 software (29) was used for statistical analysis, and p values below the 0.05 threshold were considered as the acceptable level of significance.

\section{Results}

The general sociodemographic specifications of the recruited students and their parents are presented in Table 1. Among the participant students, $14.0 \%$ had prior experience of infestation with pediculosis. Based on the feedback of referred panelists in the qualitative appraisal stage of the constructed scale's validity, the estimated instrument level of CVI (0.77) and item level of CVR (0.90) were in the acceptable range.

The approximated Kaiser-Meyer-Olkin (KMO) measure of sampling adequacy for the prearranged subscales of the CPS-HLI (decided upon the extended model of HBM) was in the range of $0.49-0.74$. The calculated RMSEA $<0.08, \chi^{2}<$ 0.05, CFI $>0.9$, and the value of Bartlett's test of sphericity which reached the statistical significance $(\mathrm{P}<0.001)$ suggested the appropriateness of the model fit to the observed study data (Table 2).

The loading values for the assigned items into the corresponding factors are tabulated in Table 3. Among the proposed subscales of the CPS-HLI, the behavior subscale accounted for $23.95 \%$ of the variance, perceived barriers and self-efficacy subscales explained 34.29 and $34.86 \%$ of the variance, respectively, perceived susceptibility and perceived severity accounted for 32.98 and $58.43 \%$ of the variance, respectively, perceived benefits and self-identity subscales indicated 46.47 and $42.20 \%$ of the variance, respectively, and the consideration of future consequences, concern for appearance, perceived importance, and cues to action subscales accounted for 42.03, 61.17, 39.07, and 73.66\% of the variance in the items, respectively. All the betrothed factors had the recommended eigenvalues greater than one (27) and the eleven-factor solution explained $44.46 \%$ of the total variance.

Those items with factor loadings smaller than 0.3 (27) were relinquished from the CPS-HLI items' list, including two items from the behavior subscale (I have combed my hairs at least twice in the recent two weeks and I have taken a shower at least twice a week in recent two weeks) with factor loadings of 0.296 and 0.259 , respectively, three items from the perceived barriers subscale (I can't reject my friends' requests to borrow my hat, scarf, etc., I can't reject my family members' request to borrow my hat, scarf, etc., and I don't know how to prevent my HLI) with factor loadings of 0.065, 0.074, and 0.293, respectively, two items from the self-efficacy subscale (I can obtain needed information about HLI and I can follow lice treatment instructions if I catch HLI accidentally) with factor loadings of 0.067 and 0.186 , respectively, and one item from the perceived susceptibility subscale (when I go to a hairdresser always my hairdressing appliances are being used) with a factor loading of 0.017 . 


\begin{tabular}{|c|c|}
\hline Demographic Variables & No. $(\%)$ \\
\hline \multicolumn{2}{|l|}{ Grade } \\
\hline 1 & $67(19.5)$ \\
\hline 2 & $59(17.2)$ \\
\hline 3 & $64(18.7)$ \\
\hline 4 & $60(17.5)$ \\
\hline 5 & $41(12)$ \\
\hline 6 & $52(15.2)$ \\
\hline \multicolumn{2}{|l|}{ Father's education } \\
\hline Illiterate & $12(3.5)$ \\
\hline Primary & $35(10.2)$ \\
\hline Secondary & $79(23)$ \\
\hline High school & $108(31.5)$ \\
\hline University & $109(31.8)$ \\
\hline \multicolumn{2}{|l|}{ Mother's education } \\
\hline Illiterate & $14(4.1)$ \\
\hline Primary & $75(21.9)$ \\
\hline Secondary & $89(25.9)$ \\
\hline High school & $112(32.7)$ \\
\hline University & $53(15.5)$ \\
\hline \multicolumn{2}{|l|}{ Father's job } \\
\hline Unemployed & $97(28.3)$ \\
\hline Self-employed & $121(35.3)$ \\
\hline Private-sector-employed & $26(7.6)$ \\
\hline Government-employed & $99(28.9)$ \\
\hline \multicolumn{2}{|l|}{ Mother's job } \\
\hline Housewife & $320(93.3)$ \\
\hline Private-sector-employed & $6(1.7)$ \\
\hline Government-employed & $17(5)$ \\
\hline \multicolumn{2}{|l|}{ Family size } \\
\hline 3 & $57(16.6)$ \\
\hline 4 & $177(51.6)$ \\
\hline 5 & $83(24.2)$ \\
\hline 6 & $19(5.5)$ \\
\hline 7 & $7(2)$ \\
\hline \multicolumn{2}{|c|}{ History of the previous $\mathrm{HL}$ infestation } \\
\hline Yes & $48(14)$ \\
\hline No & $295(86)$ \\
\hline
\end{tabular}

The estimated values of the CFI (above 0.90) and RMSEA that are indicative of reasonable model fit to the study
Table 2. Estimated Kaiser-Meyer-Olkin (KMO) Measures of Sampling Adequacy and Bartlett's Test of Sphericity for Prearranged Subscales of Children's Perception Scale of Head Lice Infestation (CPS-HLI)

\begin{tabular}{|lcc|}
\hline Constructs & KMO & Bartlett's Test (Significance) \\
\hline Behavior & 0.49 & $100.891(\mathrm{P}=0.000)$ \\
\hline Perceived susceptibility & 0.73 & $279.145(\mathrm{P}=0.000)$ \\
\hline Perceived severity & 0.65 & $130.806(\mathrm{P}=0.000)$ \\
\hline Perceived barriers & 0.65 & $231.808(\mathrm{P}=0.000)$ \\
\hline Perceived benefits & 0.74 & $337.264(\mathrm{P}=0.000)$ \\
\hline Self-efficacy & 0.64 & $112.027(\mathrm{P}=0.000)$ \\
\hline Self-identity & 0.62 & $107.272(\mathrm{P}=0.000)$ \\
\hline $\begin{array}{l}\text { Consideration of future } \\
\text { consequences }\end{array}$ & 0.60 & $107.502(\mathrm{P}=0.000)$ \\
\hline Concern for appearance & 0.74 & $412.599(\mathrm{P}=0.000)$ \\
\hline Perceived importance & 0.67 & $183.541(\mathrm{P}=0.000)$ \\
\hline Cues to action & 0.50 & $86.354(\mathrm{P}=0.000)$ \\
\hline
\end{tabular}

data are tabulated in Table 4. The path loadings for the 11factor model of the CPS-HLI are also presented in Figure 1 based on the outputs of the CFA. The estimated values of the internal consistency measure of Cronbach's Alpha and test-retest intra-class correlation coefficient are presented in Table 5.

\section{Discussion}

The main aim of this study was to develop and psychometrically analyze the properties of the CPS-HLI for application in research and practice settings. The findings revealed robust psychometric properties, including internal consistency and test-retest reliability of the CPS-HLI as a self-report scale of students' perception assessment about HLI. The 11-component structure of the CPS-HLI as guided by the extended HBM constructs (23) was confirmed based on the CFA outputs. The observed acceptable accuracy metrics of the CPS-HLI could imply its potentially adequate performance to classify young-age school children according to their levels of perception about HLI and hence to identify those with the greatest needs of knowledge support and guidance.

The proper assessment of school-age children's perception of risk factors of HLI, the effectiveness of the personal precautionary measures, and their implications for health and daily life well-being could play an imperative role in the attainment of preventive interventions' objectives. Perceptions of school-age Iranian children about HLI were examined in earlier studies (30-32). But, the application of a non-validated tool was a major methodological flaw in the implemented research. A similar challenge was also reported in international studies on children's perceptions about HLI (33). The methodological predicament 
Bekry G et al.

\begin{tabular}{lcccc}
\hline Table 4. Confirmatory Factor Analysis Model Fit to Study Data Indices in the Psychometric Appraisal of the Children's Perception Scale of Head Lice Infestation (CPS-HLI) \\
\hline Constructs & RMSEA & $\mathbf{C h i}^{\mathbf{2}}$ & CFI & TLI \\
\hline Behavior & 0.136 & - & 1 & - \\
\hline Perceived susceptibility & 0.012 & 5.251 & 0.999 & 0.998 \\
\hline Perceived severity & 0.000 & 0.000 & 1 & 1 \\
\hline Perceived barriers & 0.047 & 14.023 & 0.973 & 0.941 \\
\hline Perceived benefits & 0.063 & 11.796 & 0.979 & 0.959 \\
Self-efficacy & 0.055 & 8.102 & 0.960 & 0.901 \\
\hline Self-identity & 0.079 & 6.263 & 0.958 & 0.875 \\
Consideration of future & 0.000 & 0.413 & 1 & 1 \\
Consequences & & & 0.996 & 0.987 \\
\hline Perceived importance & 0.050 & 3.729 & 0.998 & 0.995 \\
\hline Cues to action & 0.024 & 2.400 & 1 & 1 \\
\hline
\end{tabular}

Table 5. Values of the Internal Consistency Measure of Cronbach's Alpha and Test-Retest Reliability of Intra-class Correlation (ICC) for All 11 Subscales in Psychometric Appraisal of Children's Perception Scale of Head Lice Infestation (CPS-HLI)

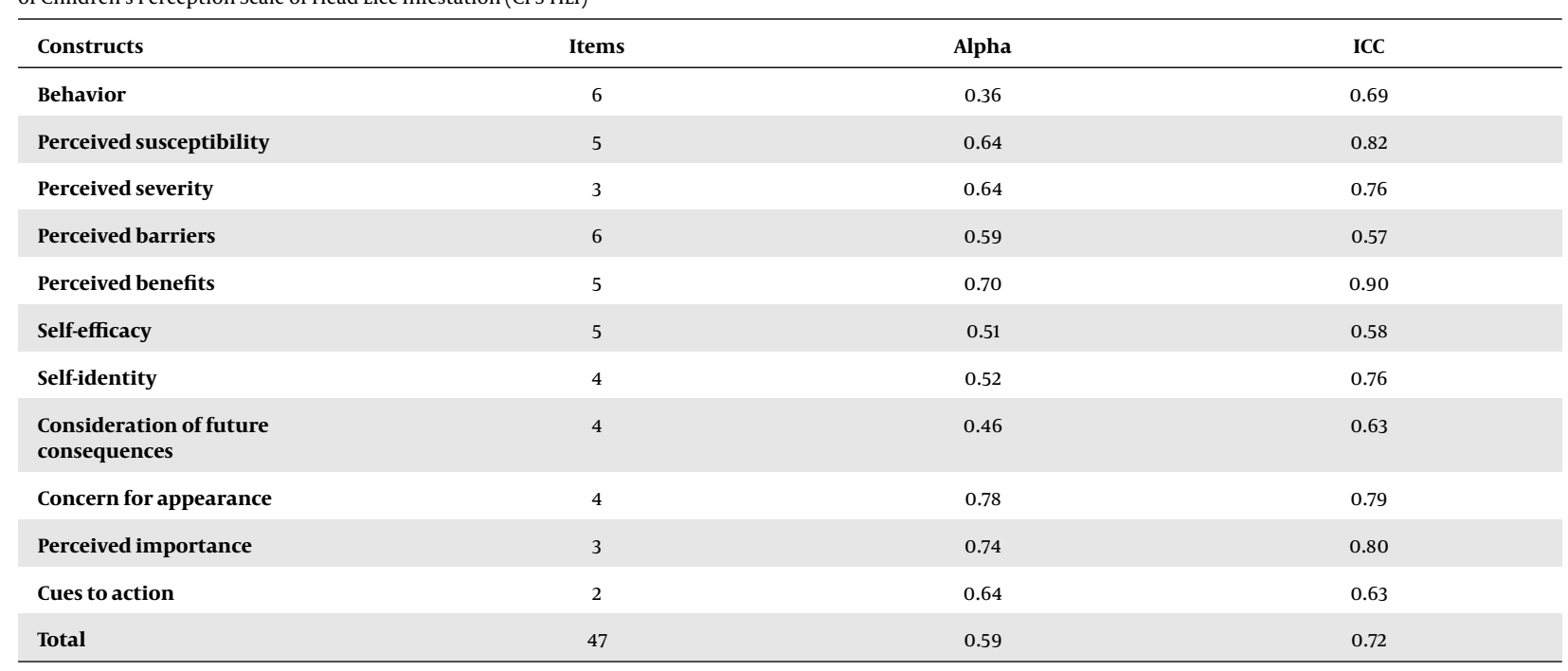

in the measurement of children's risk perceptions about different health-threatening problems and life challenges has also been addressed in studies that used researcherdesigned or validated instruments for data collection (18, 34-36). Given the methodological impediments, the ambiguity of available research evidence about perceptions of school-aged children regarding HLI needs to be resolved $(33,37)$. This knowledge gap and the need for correctional interventions, however, must be contextualized for the complex socio-economic environments that shape schoolage children and their family members' HLI-related behaviors across the world.

To the best of current knowledge, no head lice-specific tool has been developed to assess school-age children's im- pression about the potential risks of HLI and also their selfefficacy in dealing with the therapeutic recommendations. One of the main functions of the developed tool, therefore, is to provide the required data for policymakers and program implementers to make their decision based on a systematic and accurate assessment of the children's perceptions about HLI in diverse socio-cultural spheres and more specifically in the Iranian context.

Psychometric validation of the CPS-HLI in a real-life context could reveal its full potential in capturing and enumerating children's perceptions of an important health issue. The use of the extended HBM constructs (23) to frame the instrument's items is incremental and can be considered an important strength of the devised tool. 


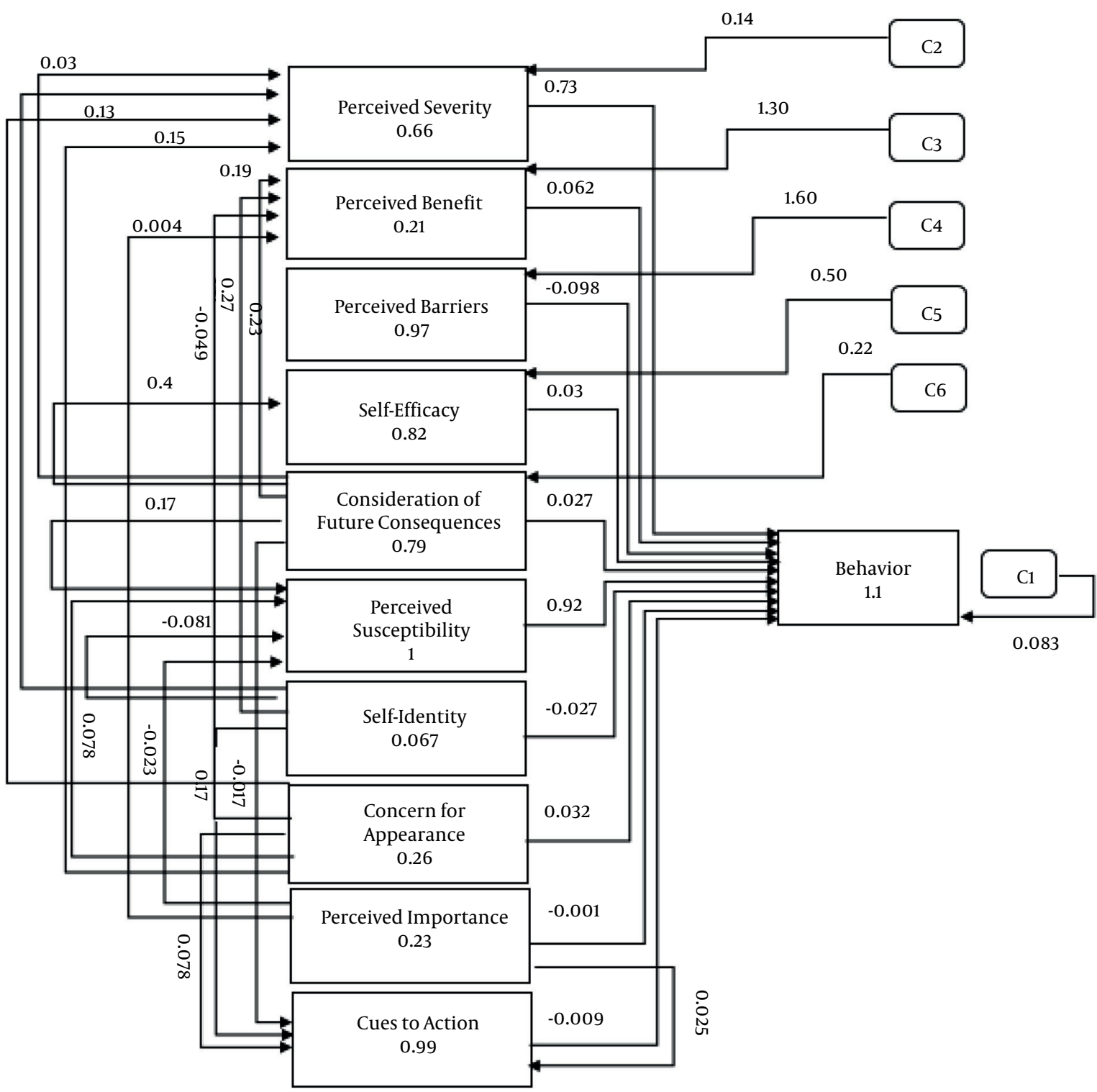

Figure 1. Path loadings in the 11-factor model of CPS-HLI based on the confirmatory factor analysis $(\mathrm{N}=343)$

Based on the study findings, the CPS-HLI distinctiveness is its congruity to split children into mutually exclusive subgroups according to their scores of perceptions about HLI risk factors, the effectiveness of personal preventive behaviors, and implications of the illness for their health and well-being.

\subsection{Limitations}

The performed study findings must be tempered by certain limitations and methodological caveats. Therefore, their interpretation should be made with caution. The in- clusion of participants from a pre-selected school with a high prevalence of HLI might represent selection bias in the enrolment of families from a definite socio-economic gradient. Non-representativeness of the recruited participants from two elementary schools in the city of Paveh (Kermanshah province, West of Iran) may also limit the external validity of the scale and generalizability of the findings to other school-age children outside the geographic boundary of the study venue. The existent stigma with HLI among the approached families and their children might also have had effects on their responses and resulted in re- 
sponse bias. The age range of the participant children (6 11 years) and their reservation or shyness in responding to questions asked by an outsider might also have posed the same bias in this study. The behavior subscale did not indicate adequate internal reliability based on the analysis results and it needs to be re-tested in future studies. Thus, the attenuated external validity of the developed tool may limit its broad applicability.

\subsection{Conclusion}

The conception of the CPS-HLI is a decisive first step in progressing towards the deterioration of head lice risk profile in communities. However, the most implicit repercussion of its introduction will be bringing the importance of children's perceptions about head lice and its prevention to the discussion and invigorate the conscience of health care providers (HCPs), health systems' policymakers, and school staff about this key aspect of pediculosis prevention strategies. Overall, the conducted study aligns well with the efforts to recognize the predictors of adapting HLIrelated preventive behaviors among school-aged children and is an important step forward to provide evidence for empirical health interventions to mitigate the HLI prevalence. Nevertheless, future research and extensive testing of the CPS-HLI on different populations of school-age children with diverse socio-economic backgrounds is imperative to appraise the external validity of the scale for its application in cross-cultural settings.

\section{Footnotes}

Authors' Contribution: Study concept and design, A. SH. and G. B.; Analysis and interpretation of data, A. SH., P.S., and H. A.; Drafting of the manuscript, G. B.; Critical revision of the manuscript for important intellectual content, A. SH. and H. A.; Statistical analysis, P. S.

Conflict of Interests: All the authors declare that they have no conflict of interest related to the design, conduct, or reporting of the research findings as presented in this manuscript.

Ethical Approval: This study received approval from the regional Medical Ethics Board of Trustees (MEBoT) affiliated with the Tabriz University of Medical Sciences (approval number: IR.TBZMED.REC.1396.187).

Funding/Support: This research was funded by the Tabriz University of Medical Sciences (grant number 5/D/4757061396-04-25).

Informed Consent: Informed consent was obtained from the children's parents.

\section{References}

1. Sangare AK, Doumbo OK, Raoult D. Management and treatment of human lice. Biomed Res Int. 2016;2016:8962685. doi: 10.1155/2016/8962685. [PubMed: 27529073]. [PubMed Central: PMC4978820].

2. Karabela Y, Yardimci G, Yildirim I, Atalay E, Karabela SN. Treatment of phthiriasis palpebrarum and crab louse: Petrolatum jelly and 1\% permethrin shampoo. Case Rep Med. 2015;2015:287906. doi: 10.1155/2015/287906. [PubMed: 26451147]. [PubMed Central: PMC4587429].

3. Cummings C, Finlay JC, MacDonald NE. Head lice infestations: A clinical update. Paediatr Child Health. 2018;23(1):e18-24. doi: 10.1093/pch/pxx165. [PubMed: 29479286]. [PubMed Central: PMC5814977].

4. Tufail M, Khan M, Hassan I. Prevalence of pediculosis among students in Pakistan. Arch Med. 2017;9(2). doi: 10.21767/1989-5216.1000207.

5. Burkhart CN, Burkhart CG. Head lice: scientific assessment of the nit sheath with clinical ramifications and therapeutic options. JAm Acad Dermatol. 2005;53(1):129-33. doi: 10.1016/j.jaad.2005.01.134. [PubMed: 15965432].

6. Canyon DV, Speare R, Muller R. Spatial and kinetic factors for the transfer of head lice (Pediculus capitis) between hairs. J Invest Dermatol. 2002;119(3):629-31. doi: 10.1046/j.1523-1747.2002.00540.x. [PubMed: 12230505$]$.

7. Gratz NG; World Health Organization. Human lice: Their prevalence, control and resistance to insecticides: A review 1985-1997. Geneva, Switzerland: World Health Organization; 1997.

8. Hansen RC, O'Haver J. Economic considerations associated with Pediculus humanus capitis infestation. Clin Pediatr (Phila). 2004;43(6):523-7. doi: 10.1177/000992280404300603. [PubMed: 15248004].

9. Al-Shawa RM. Pediculus capitis, infestation according to sex and social factors in Gaza Governorate. IUG Journal of Natural Studies. 2015;16(1).

10. Davarpanah MA, Rasekhi Kazerouni A, Rahmati H, Neirami RN, Bakhtiary H, Sadeghi M. The prevalence of pediculus capitis among the middle schoolchildren in Fars Province, southern Iran. Caspian J Intern Med. 2013;4(1):607-10. [PubMed: 24009945]. [PubMed Central: PMC3762237].

11. Moosazadeh M, Afshari M, Keianian H, Nezammahalleh A, Enayati AA. Prevalence of head lice infestation and its associated factors among primary school students in Iran: A systematic review and meta-analysis. Osong Public Health Res Perspect. 2015;6(6):346-56. doi: 10.1016/j.phrp.2015.10.011. [PubMed: 26835244]. [PubMed Central: PMC4700766].

12. Doroodgar A, Sadr F, Doroodgar M, Doroodgar M, Sayyah M. Examining the prevalence rate of Pediculus capitis infestation according to sex and social factors in primary school children. Asian PacJ Trop Dis. 2014;4(1):25-9. doi: 10.1016/s2222-1808(14)60308-x.

13. Fakoorziba MR, Moemenbellah-Fard MJ, Nasiri Z, Azizi K. Head lice treatment with two interventions: Pediculosis capitis profile in female schoolchildren of a rural setting in the south of Iran. Ann Trop Med Public Health. 2016;9(4):245. doi: 10.4103/1755-6783.184790.

14. Nazari M, Goudarztalejerdi R, Anvari Payman M. Pediculosis capitis among primary and middle school children in Asadabad, Iran: An epidemiological study. Asian Pac J Trop Biomed. 2016;6(4):367-70. doi: 10.1016/j.apjtb.2016.03.002.

15. Sayyad S, Vahabi A, Vahabi B, Sayyadi M, Ahmadian M. Head louse (Pediculus humanus capitis) infestation in primary schoolchildren in rural areas of Paveh County, Kermanshah province. Int J Pharm Chem Sci. 2016;974:2115.

16. Vahabi A, Shemshad K, Sayyadi M, Biglarian A, Vahabi B, Sayyad S, et al. Prevalence and risk factors of Pediculus (humanus) capitis (Anoplura: Pediculidae), in primary schools in Sanandaj City, Kurdistan Province, Iran. Trop Biomed. 2012;29(2):207-11. 
17. Shadick NA, Zibit MJ, Nardone E, DeMaria AJ, Iannaccone CK, Cui J. A school-based intervention to increase lyme disease preventive measures among elementary school-aged children. Vector Borne Zoonotic Dis. 2016;16(8):507-15. doi: 10.1089/vbz.2016.1942. [PubMed: 27248436]. [PubMed Central: PMC4960477]

18. Atwa ZT, Wahed WYA. The impact of illness perception and socioclinico-demographic factors on perceived quality of life in children and adolescents with thalassemia intermedia. Pediatr Blood Cancer. 2012;66(7). e27735. doi: 10.1002/pbc.27735. [PubMed: 30924610].

19. Kalari H, Soltani A, Azizi K, Faramarzi H, Moemenbellah-Fard MD. Comparative efficacy of three pediculicides to treat head lice infestation in primary school girls: a randomised controlled assessor blind trial in rural Iran. BMC Dermatol. 2019;19(1):13. doi: 10.1186/s12895-0190093-5. [PubMed: 31510998]. [PubMed Central: PMC6739928].

20. Babazadeh T, Kouzekanani K, Oliaei S, Gaffari-Fam S, Abbasabad GD, Maleki Chollou K, et al. Assessing the link between head lice infestation and selected cognitive-behavioral factors in a sample of Iranian female adolescents. Heliyon. 2020;6(5). e03959. doi: 10.1016/j.heliyon.2020.e03959. [PubMed: 32514477]. [PubMed Central: PMC7266778].

21. Ghofleh Maramazi H, Sharififard M, Jahanifard E, Maraghi E, Mahmoodi Sourestani M, Saki Malehi A, et al. Pediculosis humanus capitis prevalence as a health problem in girl's elementary schools, Southwest of Iran (2017-2018). J Res Health Sci. 2019;19(2). e00446. [PubMed: 31278215]. [PubMed Central: PMC7183542].

22. Caldarera AM, Marengo D, Gerino E, Brustia P, Rolle L, CohenKettenis PT. A Parent-Report Gender Identity Questionnaire for children: Psychometric properties of an Italian version. Arch Sex Behav. 2019;48(5):1603-15. doi: 10.1007/s10508-018-1372-7. [PubMed: 30810957]. [PubMed Central: PMC6594981].

23. Orji R, Vassileva J, Mandryk R. Towards an effective health interventions design: an extension of the health belief model. Online $J$ Public Health Inform. 2012;4(3). doi: 10.5210/ojphi.v4i3.4321. [PubMed: 23569653]. [PubMed Central: PMC3615835].

24. Ott RL, Longnecker MT. An introduction to statistical methods and data analysis. Boston, MA, USA: Cengage Learning; 2015.

25. Lawshe $\mathrm{CH}$. A quantitative approach to content validity. Pers Psychol. 1975;28(4):563-75. doi: 10.1111/j.1744-6570.1975.tb01393.x.

26. Mokkink LB, Terwee CB, Patrick DL, Alonso J, Stratford PW, Knol DL, et al. The COSMIN study reached international consensus on taxonomy, terminology, and definitions of measurement properties for healthrelated patient-reported outcomes.J Clin Epidemiol. 2010;63(7):737-45. doi: 10.1016/j.jclinepi.2010.02.006. [PubMed: 20494804].

27. Kartal A, Ozsoy SA. Validity and reliability study of the Turkish version of Health Belief Model Scale in diabetic patients. Int J Nurs Stud.
2007;44(8):1447-58. doi: 10.1016/j.ijnurstu.2007.06.004. [PubMed: 17655849].

28. Souza AC, Alexandre NMC, Guirardello EB. Psychometric properties in instruments evaluation of reliability and validity. Epidemiol Serv Saude. 2017;26(3):649-59. doi: 10.5123/S1679-49742017000300022. [PubMed: 28977189].

29. Mehmetoglu M, Jakobsen TG. Applied statistics using Stata: a guide for the social sciences. California, USA: Sage; 2016.

30. Kassiri H, Mehraghaei M. Assessment of the prevalence of pediculosis capitis and related effective features among primary schoolchildren in Ahvaz County, Southwest of Iran. Environ Sci Pollut Res Int. 2021;28(18):22577-87. doi: 10.1007/s11356-020-12284-9. [PubMed: 33420692].

31. Moshki M, Mojadam M, Zamani Alavijeh F. [Preventive behaviors of female elementary students in regard to Pediculosis infestation based on Health Belief Model (HBM)]. Health Dev J. 2014;3(3):269-81. Persian.

32. Nejati J, Keyhani A, Tavakoli KareshkA, Mahmoudvand H, Saghafipour A, Khoraminasab M, et al. Prevalence and risk factors of pediculosis in primary school children in South West of Iran. Iran J Public Health. 2018;47(12):1923-9. [PubMed: 30788308]. [PubMed Central: PMC6379608].

33. Sidoti E, Bonura F, Paolini G, Tringali G. A survey on knowledge and perceptions regarding head lice on a sample of teachers and students in primary schools of north and south of Italy. J Prev Med Hyg. 2009;50(3):141-9. quiz 150-1. [PubMed: 20411647].

34. Broc MA. Harter's self-perception profile for children: An adaptation and validation of the Spanish version. Psychol Rep. 2014;115(2):444-66. doi: 10.2466/08.07.PR0.115c22z5. [PubMed: 25259937].

35. Ferguson A, Del Donno C, Obeng-Gyasi E, Mena K, Kaur Altomare T, Guerrero R, et al. Children exposure-related behavior patterns and risk perception associated with recreational beach use. Int J Environ Res Public Health. 2019;16(15). doi: 10.3390/ijerph16152783. [PubMed: 31382616]. [PubMed Central: PMC6696461].

36. Munoz-Quezada MT, Lucero B, Bradman A, Steenland K, Zuniga L, Calafat AM, et al. An educational intervention on the risk perception of pesticides exposure and organophosphate metabolites urinary concentrations in rural school children in Maule Region, Chile. Environ Res. 2019;176:108554. doi: 10.1016/j.envres.2019.108554. [PubMed: 31288198]. [PubMed Central: PMC7953381].

37. Yingklang M, Sengthong C, Haonon O, Dangtakot R, Pinlaor P, Sota C, et al. Effect of a health education program on reduction of pediculosis in school girls at Amphoe Muang, Khon Kaen Province, Thailand. PLoS One. 2018;13(6). e0198599. doi: 10.1371/journal.pone.0198599. [PubMed: 29889851]. [PubMed Central: PMC5995376]. 
Table 3. Items' Factor Loadings in the Predetermined 11-factor Model of Children's Perception Scale of Head Lice Infestation (CPS-HLI) ( N = 343).

\begin{tabular}{|c|c|}
\hline Subscales & Factor Loadings \\
\hline \multicolumn{2}{|l|}{ Behavior } \\
\hline My parents have checked my hairs for lice/nits in the recent two weeks. & 0.712 \\
\hline I have combed my hair at least twice in the recent two weeks. & 0.296 \\
\hline My hairs have been checked by my school authorities for lice/nits in the recent month. & 0.424 \\
\hline My scarf is washed by my parents or myself at least once a week. & 0.469 \\
\hline I have taken a shower at least twice a week in recent two weeks. & 0.259 \\
\hline \multicolumn{2}{|l|}{ Perceived barriers } \\
\hline Combing my hair is a time-consuming job for me. & 0.782 \\
\hline Taking a shower is a demanding experience for me. & 0.727 \\
\hline I can't manage to take a shower at least twice a week. & 0.617 \\
\hline I can't reject my friends' requests to borrow my hat, scarf, etc. & 0.065 \\
\hline I can't reject my family members' request to borrow my hat, scarf, etc. & 0.074 \\
\hline I don't know how to prevent my hair lice infestation. & 0.293 \\
\hline \multicolumn{2}{|l|}{ Self-efficacy } \\
\hline I can take a shower whenever I want. & 0.779 \\
\hline Combing my hair several times a day is easy for me. & 0.745 \\
\hline I can comfortably talk with my parents, teachers, and the school health officer about my hair lice infestation. & 0.513 \\
\hline I can obtain needed information about hair lice infestation. & -0.067 \\
\hline I can follow lice treatment instructions if I catch hair lice infestation accidentally. & 0.186 \\
\hline \multicolumn{2}{|l|}{ Perceived susceptibility } \\
\hline I may catch head lice infestation even if I had not the disease earlier. & 0.766 \\
\hline It is probable that I catch head lice infestation in the near future. & 0.716 \\
\hline It is probable that I catch head lice infestation at the school I am studying. & 0.574 \\
\hline I am worried about my head lice infestation. & 0.468 \\
\hline When I go to a hairdresser, my hairdressing appliances are always used. & 0.017 \\
\hline Head lice infestation might cause me to lose my friends. & 0.759 \\
\hline Head lice infestation might cause severe itching and impatience. & 0.766 \\
\hline \multicolumn{2}{|l|}{ Perceived benefit } \\
\hline By preventing head lice infestation, I will not be pledged to use anti-lice shampoos. & 0.818 \\
\hline By preventing head lice infestation, I will be more successful in my studies. & 0.789 \\
\hline By preventing head lice infestation, I will have more friends around. & 0.783 \\
\hline Prevention of head lice infestation is cheaper than its treatment. & 0.489 \\
\hline Head lice timely treatment can prevent its spread to others. & 0.425 \\
\hline \multicolumn{2}{|l|}{ Self-identity } \\
\hline If I will be infested with head lice, I think I could follow the treatment plan. & 0.748 \\
\hline I could implement correctly the head lice infestation prevention procedures. & 0.744 \\
\hline I see myself as a healthy hair person. & 0.638 \\
\hline I can use only my personal hat, scarf, comb and etc. while at home. & 0.410 \\
\hline \multicolumn{2}{|l|}{ Consideration of future consequences } \\
\hline Head lice infestation consequences are important to me even if there will be a low chance of its occurrence. & 0.747 \\
\hline Even if the head lice infestation consequences do occur a couple of years later, I should take it seriously. & 0.699 \\
\hline I can guess the consequence if I don't care about my hairs' health. & 0.603 \\
\hline Since every individual could catch head lice infestations, I should take care of my hair. & 0.521 \\
\hline \multicolumn{2}{|l|}{ Concern for appearance } \\
\hline Head lice infestation could make a person weak and lethargic. & 0.869 \\
\hline Head lice infestation could make a person anemic and pale. & 0.807 \\
\hline
\end{tabular}


Head lice infestation could affect a person's mood and make him/her unwilling to devote enough attention to appearance.

\section{Perceived importance}

Head lice infestation may prevent my friends from playing with me.

Head lice infestation might prevent my attendance at family parties.

I don't like to play with those children who have a head lice infestation.

0.547

Cues to action

The school health officer has talked with me about head lice infestation. 